\title{
Nurses as essential members of an effective in-hospital cardiac resuscitation team
}

\author{
Tabitha L. Cumpian, Babak Yasmeh, Arshad Jahangir \\ Center for Advanced Atrial Fibrillation Therapies, Aurora Cardiovascular and Thoracic Services, Aurora Sinai/Aurora St. Luke's Medical Centers, \\ University of Wisconsin School of Medicine and Public Health, Milwaukee, WI, USA \\ Correspondence to: Arshad Jahangir, MD. Center for Advanced Atrial Fibrillation Therapies, Aurora Cardiovascular and Thoracic Services, Aurora \\ Sinai/Aurora St. Luke's Medical Centers, University of Wisconsin School of Medicine and Public Health, 2801 W. Kinnickinnic River Parkway, Ste. \\ 880, Milwaukee, WI 53215, USA. Email: publishing44@aurora.org. \\ Comment on: Guetterman TC, Kellenberg JE, Krein SL, et al. Nursing roles for in-hospital cardiac arrest response: higher versus lower performing \\ hospitals. BMJ Qual Saf 2019;28:916-24.
}

Received: 24 January 2020; Accepted: 21 April 2020; Published: 25 June 2020.

doi: $10.21037 /$ jhmhp-20-18

View this article at: http://dx.doi.org/10.21037/jhmhp-20-18

In-hospital cardiac arrest (IHCA), defined as loss of circulation prompting resuscitation with chest compressions, defibrillation, or both, is an increasingly common event affecting healthcare systems worldwide (1). The Get With The Guidelines-Resuscitation (GWTG-R) registry, a large, prospective, hospital-based clinical registry, documented an average of 209,000 cases of IHCA each year in the United States between 2003 and 2007, with an increase to 292,000 per year between 2008 and 2017 (1,2). Survival rates for IHCA remain poor $(3,4)$ with average survival rates of about 26\% among 311 hospitals in the United States in 2017 (2). The rate of survival to hospital discharge after cardiac arrest varies among medical centers and is higher in hospitals with higher cardiac arrest volume, higher surgical volume, greater availability of invasive cardiac services, and more affluent catchment areas (2). Among those surviving to hospital discharge, $81.7 \%$ were considered to possess good functional status as evidenced by a cerebral performance category of 1 or 2 (2), representing mild or no neurologic disability to moderate neurologic disability (5).

A significant difference in survival rates exists across hospitals in the United States, with survival rates ranging from $5.3-49.6 \%(3,6)$. This wide variation is present despite published guidelines by the American Heart Association (AHA) for the management of cardiac arrest. Even with guidelines in place, implementation of recommended procedures during IHCA has proved difficult as these events take place in varied environments with complex and diverse medical issues and require the collaboration of a multidisciplinary team to achieve successful outcomes. There are several factors involved and multiple steps are needed to ensure effective management of an IHCA patient.

The initial step in the evaluation and treatment of IHCA requires timely identification of the cardiac arrest event and the underlying cause. When a cardiac arrest occurs, early appropriate initiation of cardiopulmonary resuscitation (CPR) with quality chest compressions and thorough postresuscitation care are crucial to a positive outcome $(1,5,7)$. In approximately $50-60 \%$ of cases, the underlying cause is cardiac in nature, whereas $15-40 \%$ are due to respiratory insufficiency (1) and appropriate care is needed for each of the underlying conditions and modifying factors to prevent deterioration that might lead to cardiac arrest. Development of a dedicated cardiac arrest or code team is essential. Top-performing hospitals are found to have dedicated or designated resuscitation teams with additional support staff (i.e., nursing, pharmacy, clerical, spiritual staff), clear patterns of communication between team members, and specific training and education around resuscitation (7). Although ample research has been performed regarding procedural techniques for the evaluation and management of IHCA, investigation into healthcare professionals' roles, particularly the role of nurses, during a cardiac arrest event is limited.

Guetterman et al. (8) addressed this issue through a secondary analysis of qualitative data to examine the roles of 
nurses during resuscitation care across a wide spectrum of hospitals. This analysis was intended to assist in identifying nursing-focused strategies that may be linked to better IHCA outcomes. The study was completed by conducting semi-structured interviews at nine hospitals participating in the AHA's GWTG-R registry that varied in geography, academic status, and risk-standardized IHCA survival. Hospitals were categorized into performance quartiles based on risk-standardized rates of survival to discharge. The study included higher-performing, middle-performing, and lower-performing hospitals.

The main finding of the study is that higher-performing hospitals emphasized the role of nurses as bedside first responders, resuscitation team members, and administrative leaders. These hospitals provide training, organizational flexibility, and support to nurses. Likewise, higherperforming hospitals empowered nurses to function at higher levels of clinical practice, including leading bedside defibrillation when possible. In addition, they also encouraged nurses to become leaders in resuscitation care either by being an administrator that further supported the bedside nurses, being the resuscitation team leader during the cardiac arrest event, or as clinical champions for resuscitation care. Overall, the study found that higherperforming hospitals had a more permissive role for nurses during cardiac arrest events, whereas lower-performing hospitals had more restrictive roles for nurses during resuscitation care.

The major strength of this research is that the study sampled hospitals across the United States that varied on four characteristics: geographic region, academic status, number of beds, and risk-standardized IHCA survival. The researchers were able to identify numerous roles nurses hold in the care of patients experiencing an IHCA event as well as important differences in the support nurses receive at higher- and lower-performing hospitals. The positive impact of mentoring, debriefing, and empowering nurses at hospitals that performed more highly in terms of IHCA patient care and outcomes were also identified. The study provides much-needed information to help formulate standardization of policies across a spectrum of hospitals in training and mentoring their work force to achieve better outcomes for patients with IHCA.

A limitation of this study is that causal inferences regarding IHCA could not be drawn, which is rightly acknowledged by the investigators. In addition, the primary investigators were unblinded to the hospitals' performance levels, and information about IHCA processes was obtained through self-reporting by hospital personnel; therefore, a potential for bias exists. The information gathered was attained from a larger study in which the focus was on IHCA processes and outcomes, not specifically on nursing, which may have affected the results.

This study clearly demonstrates the impact and role nurses have at the bedside in caring for patients who develop IHCA. Further research is needed to elucidate the role of other healthcare team members, such as the pharmacist and support staff who participate during the management of IHCA. The roles and impact of various medical professionals in the prevention of IHCA, prompt treatment response, and post-event care need to be better defined to appreciate the full picture of the healthcare team in improving outcomes after an IHCA event $(9,10)$.

This is important in view of numerous studies demonstrating that improving care of patients at risk of IHCA events begins with prevention. As such, it has now been added as the first link in the Chain of Survival for IHCA in the AHA guidelines for CPR and Emergency Cardiovascular Care (1). Healthcare institutions must work to establish a system that allows healthcare providers from across the medical spectrum to rapidly and accurately identify at-risk or deteriorating patients and create appropriate interventional responses such as the activation of rapid response teams (1). As each passing minute without intervention following cardiac arrest decreases the likelihood of disability-free survival, the provision of high-quality care by first responders at the bedside and the quality of cardiac arrest treatment, including CPR, must be improved to enhance survival rates and overall outcomes $(10,11)$. Hospital staff, including nurses, pharmacists, and physicians must be adequately educated and properly trained to deliver the best possible care in team environments (11). Once return of spontaneous circulation is achieved, post-cardiac arrest care should be initiated quickly to establish hemodynamic and neurologic stability $(1,9)$. The Institute of Medicine (11) has suggested an effort to standardize training and performance-evaluation measures for cardiac arrest treatment to promote a more rapid and uniform adoption and assessment of high-quality care on a national scale. Implementation of continuous quality improvement initiatives with more proactive and responsive care models, tracking of system performance, an emphasis on accountability, and ensuring that personnel are trained to respond competently to cardiac arrest are needed measures across hospital systems to improve the likelihood of overall survival and favorable neurologic outcomes 
following a cardiac arrest (11).

\section{Acknowledgments}

The authors thank Jennifer Pfaff and Susan Nord of Aurora Cardiovascular and Thoracic Services for their assistance. Funding: None.

\section{Footnote}

Provenance and Peer Review: This article was commissioned by the editorial office, Fournal of Hospital Management and Health Policy. The article did not undergo external peer review.

Conflicts of Interest: All authors have completed the ICMJE uniform disclosure form (available at http://dx.doi. org/10.21037/jhmhp-20-18). The authors have no conflicts of interest to declare.

Ethical Statement: The authors are accountable for all aspects of the work in ensuring that questions related to the accuracy or integrity of any part of the work are appropriately investigated and resolved.

Open Access Statement: This is an Open Access article distributed in accordance with the Creative Commons Attribution-NonCommercial-NoDerivs 4.0 International License (CC BY-NC-ND 4.0), which permits the noncommercial replication and distribution of the article with the strict proviso that no changes or edits are made and the original work is properly cited (including links to both the formal publication through the relevant DOI and the license). See: https://creativecommons.org/licenses/by-nc-nd/4.0/.

\section{References}

1. Andersen LW, Holmberg MJ, Berg KM, et al. In-hospital cardiac arrest: a review. JAMA 2019;321:1200-10.

doi: $10.21037 /$ jhmhp-20-18

Cite this article as: Cumpian TL, Yasmeh B, Jahangir A. Nurses as essential members of an effective in-hospital cardiac resuscitation team. J Hosp Manag Health Policy 2020;4:17.
2. Benjamin EJ, Muntner P, Alonso A, et al. Heart disease and stroke statistics-2019 update: a report from the American Heart Association. Circulation 2019;139:e56-528.

3. Schluep M, Gravesteijn BY, Stolker RJ, et al. One-year survival after in-hospital cardiac arrest: a systematic review and meta-analysis. Resuscitation 2018;132:90-100.

4. Sandroni C, Nolan J, Cavallaro F, et al. In-hospital cardiac arrest: incidence, prognosis and possible measures to improve survival. Intensive Care Med 2007;33:237-45.

5. Girotra S, Nallamothu BK, Spertus JA, et al. Trends in survival after in-hospital cardiac arrest. N Engl J Med 2012;367:1912-20.

6. Dukes K, Bunch JL, Chan PS, et al. Assessment of rapid response teams at top-performing hospitals for in-hospital cardiac arrest. JAMA Intern Med 2019. [Epub ahead of print].

7. Neumar RW, Shuster M, Callaway CW, et al. Part 1: Executive summary: 2015 American Heart Association guidelines update for cardiopulmonary resuscitation and emergency cardiovascular care. Circulation 2015;132:S315-67.

8. Guetterman TC, Kellenberg JE, Krein SL, et al. Nursing roles for in-hospital cardiac arrest response: higher versus lower performing hospitals. BMJ Qual Saf 2019;28:916-24.

9. Peltan ID, Poll J, Sorensen J, et al. Clinician perspectives regarding in-hospital cardiac arrest resuscitation: a multicenter survey. Crit Care Med 2019;47:e190-7.

10. Chan PS, Krein SL, Tang F, et al. Resuscitation practices associated with survival after in-hospital cardiac arrest: a nationwide survey. JAMA Cardiol 2016;1:189-97.

11. National Academies of Sciences, Engineering, and Medicine; Health and Medicine Division; Board on Population Health and Public Health Practice. Exploring Strategies to Improve Cardiac Arrest Survival: Proceedings of a Workshop. Washington, DC: National Academies Press (US), 2016. Available online: https://www.ncbi.nlm. nih.gov/books/NBK424951/ 